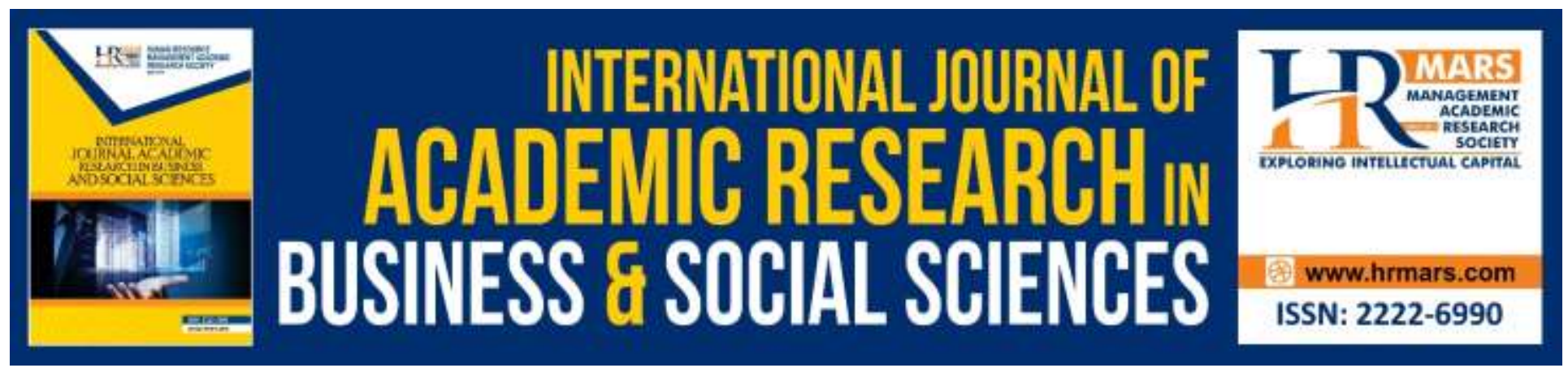

\title{
Emotion Detection among Muslims and Non- Muslims While Listening to Quran Recitation Using EEG
}

Mohamed Hamada Jasim, Mahmood Maher Salih, Ziadoon. T. Abdulwahhab, Moceheb Lazam Shouwandy, Mohamed Aktham Ahmed, Mohammed A. ALsalem, Abdulniser K. Hamzah

To Link this Article: http://dx.doi.org/10.6007/IJARBSS/v9-i14/6500

DOI:10.6007/IJARBSS/v9-i14/6500

Received: 02 August 2019, Revised: 14 August 2019, Accepted: 02 September 2019

Published Online: 23 September 2019

In-Text Citation: (Jasim et al., 2019)

To Cite this Article: Jasim, M. H., Salih, M. M., Abdulwahhab, Z. T., Shouwandy, M. L., Ahmed, M. A., \& ALsalem, M. A. (2019). Emotion Detection among Muslims and Non- Muslims While Listening To Quran Recitation Using EEG. International Journal of Academic Research in Business and Social Sciences, 9(14), 10-16.

Copyright: (C) 2019 The Author(s)

Published by Human Resource Management Academic Research Society (www.hrmars.com)

This article is published under the Creative Commons Attribution (CC BY 4.0) license. Anyone may reproduce, distribute, translate and create derivative works of this article (for both commercial and non-commercial purposes), subject to full attribution to the original publication and authors. The full terms of this license may be seen

at: http://creativecommons.org/licences/by/4.0/legalcode

Vol. 9, No. 14, Special Issue: Education 4.0: Future Learning, Pg. 10 - 16

Full Terms \& Conditions of access and use can be found at http://hrmars.com/index.php/pages/detail/publication-ethics 


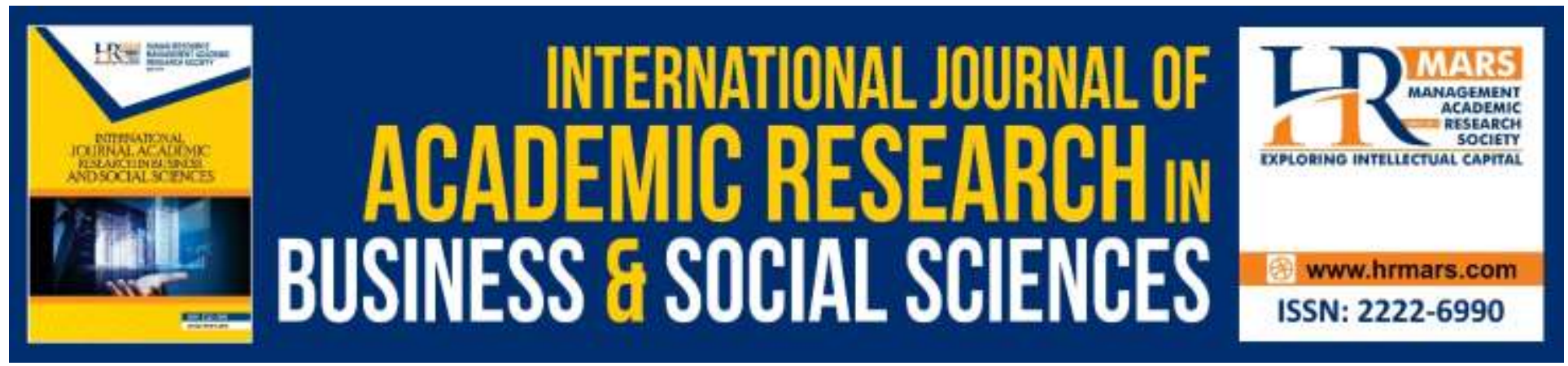

\title{
Emotion Detection among Muslims and Non- Muslims while Listening to Quran Recitation Using EEG
}

Mohamed Hamada Jasim ${ }^{1}$, Mahmood Maher Salih,1,2, Ziadoon. T. Abdulwahhab ${ }^{1,2}$, Moceheb Lazam Shouwandy ${ }^{1,2}$, Mohamed Aktham Ahmed ${ }^{1,2}$, Mohammed A. ALsalem ${ }^{1,3}$, Abdulniser K. Hamzah $^{1}$

${ }^{1}$ Fskik, Upsi, My, ${ }^{2} \mathrm{Ccms}$, Tu, Iq, ${ }^{3}$ Uomousl, Iq

Email: mohamed_941531@yahoo.com,moceheb@tu.edu.iq,mohammedasum@yahoo.com

\begin{abstract}
Significant interest from numerous disciplines has been attracted through emotion modelling and identification. Quantifying physiological signals still remain as one of the less-investigated aspects although many qualitative studies have been carried out on emotion. Thus, this study is done to examine various human emotions shown by subjects while listening to recitations of Quranic verses. The brain activities for four groups; one group of Muslim participants who understand the language of Al-Quran while the other group doesn't, one group of non-Muslims who understand the language of Al-Quran while the other group doesn't respectively is also analyzed. EEG device is used to record the brain waves while listening to Quran recitations. MFCC and KDE are used as the feature extraction to extract the features from EEG signals. Multilayer Perceptron (MLP) is used for the classification. The emotions determined from listening to Quran recitation will help to provide more information to the medical field to treat both Muslims and non-Muslims stress or depressed patients.
\end{abstract}

Keywords: Quran recitation, EEG, Human Emotion, MFCC and KDE

\section{Introduction}

Significant interest from numerous disciplines which consist of computer science, cognitive science and psychology has been attracted through emotion modelling and identification. Quantifying physiological signals still remain as one of the less-investigated aspects although many qualitative studies have been carried out on emotion. Thus, this study is done to examine various human emotions shown by subjects while listening to recitations of Quranic verses. 
Besides understanding, this study also focuses on analyzing the activities of brain for four groups; one group of Muslim participants who understand the language of Al-Quran while the other group doesn't. On the other hand, the other two groups consist of non-Muslims who understand the language of Al-Quran while the other group doesn't respectively. Emotions are not only related to every activity in humans' daily life. It also acts as a vital role in non-verbal communication. Areas of the brain that control thinking, reasoning, and decision making are also influenced by feelings. Specific physical reactions like increasing heart rate and hypertension is produced due to deep emotions. Based on the findings by Li, Chai, Kaixiang, Wahab, \& Abut, 2009 and Othman, Wahab, Karim, Dzulkifli, \& Alshaikli, 2013, human attention are also affected due to copious distressing elements. Individual reactions to stressful situations leads to negative emotions whereas individual reactions to pleasing and calm situations leads to positive emotions.

Stress treatment has been the subject of numerous studies as the most common problems faced by people these days are stress and psychological disorders. As suggested by some of the studies, Quran can help to treat stress and psychological disorders because in order to heal human psychological disorders, Quran was and is still used. Quran has also been used for ages by the Muslims for healing and treating people who suffer from stress and psychological disorders. Mahjoob, Nejati, Hosseini, \& Bakhshani, 2014 conducted a study to determine that good mental health and greater peace can be achieved by listening to Quran. According to Kimiaee, Khademian, \& Farhadi, 2012, Quran can also act as an effective resource to cope with modern stresses and challenges as Quran memorization can also improve humans' mental health besides affecting the internal factors. In order to reduce daily stress and bring peace and serenity to the heart, Atarodi, Mottaghi, \& Atarodi, 2012; Hamidi, Bagherzadeh, \& Gafarzadeh, 2010; Khan et al., 2010; Kimiaee et al., 2012; Mahjoob et al., 2014; Mottaghi, Esmaili, \& Rohani, 2011; Siahpoosh, 2012 and Zulkurnaini, Kadir, Murat, \& Isa, 2012 have conducted studies on the effects of listening to Quranic recitations. Several researchers are interested in topics related to the effect of Quran on human brain. Atarodi et al., 2012 and Mottaghi et al., 2011 found that very little scientific research is available concerning the psychological effects of the Quran despite the numerous amount of research on the relationship between religious perceptions and psychological variables.

This study aims to determine the emotional effects of listening to the Quran for all the four study groups and to compare the performance of extracting emotions using psychological methods through computational methods. Studies conducted on human emotions and their relationship to Quranic recitations will not only help people in releasing stress but the effects of listening to Quran can also be understood by psychologists, health practitioners and therapists. This research will lead to a new approach in the medicine field based on listening to Quranic recitations that can be applied in different disciplines to heal and treat both Muslims as well as non-Muslims. According to Ebrahimi, 2011, Quran helps to maintain a balance between various aspects of human life. Mahjoob et al., 2014 on the other hand found that Quran has been often used in Islamic medicine to promote health and treat people who suffer from stress and psychological disorders. Stress therapy has been the subject of numerous previous studies as stress and psychological disorders are common problems faced by people these days. Quran has been suggested by a number of these studies as a way to treat stress and psychological disorders. 
Figure 1 shows a two- dimensional emotion model that consists of a horizontal axis and a vertical axis that represents valence and arousal respectively. According to Wang, Nie, \& Lu, 2014, emotions that range from unpleasant to pleasant are referred to as valence whereas emotions that range from calm to excited are referred to arousal.

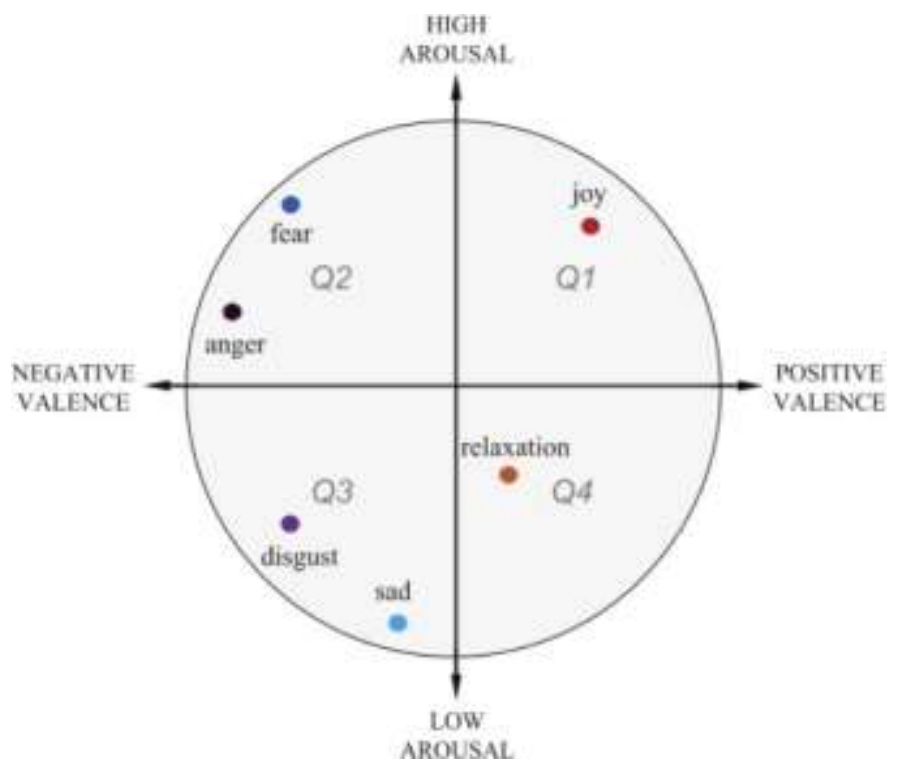

Figure 1: Two- dimensional emotion model

A study by Zulkurnaini et al., 2012, stated that the electrical signals in the form of brain waves produced by brain can be classified into four types: alpha, delta, beta, and theta. Figure 2 shows the type of brain waves, its frequency and the activities related to the brain waves.

\begin{tabular}{|l|l|l|}
\hline Brain wave & Freq. $(\mathrm{Hz})$ & Description \\
\hline Alpha & $8-13$ & Calm and alert state of consciousness \\
\hline Beta & $14-30$ & Busy thinking \\
\hline Delta & $0.5-3$ & Deep sleep \\
\hline Theta & $4-7$ & Drowsiness \\
\hline
\end{tabular}

Figure 2: Type of brain waves, its frequency and the activities related to the brain waves. 
INTERNATIONAL JOURNAL OF ACADEMIC RESEARCH IN BUSINESS AND SOCIAL SCIENCES

Vol. 9, No. 14, Special Issue: Education 4.0: Future Learning. 2019, E-ISSN: 2222-6990 @ 2019 HRMARS

Electroencephalogram (EEG) is one the tools used to measure electric activity deep inside human brain. In order to take an EEG, an individual has to wear a futuristic-looking headgear with numerous electrodes on its surface. The function of the electrodes are to sense the small electrical impulses that are constantly circulating in the human brain. EEG brings benefits to the users as EEG scans are simple and not costly. However, poor spatial resolution may lead to the drawback of EEG. EEG data gathering is classified under the non-invasive type and is pain-free. EEG data collection usually requires subjects to put on an EEG cap, moist detector net, or to have dry electrodes positioned on their heads. According to Yordanova \& Kolev, 2008, any three different measurements; time, frequency, and amplitude are usually used to analyze variations in EEG waves. Analysis of EEG amplitude is usually linked with the equivalent wave behavior.

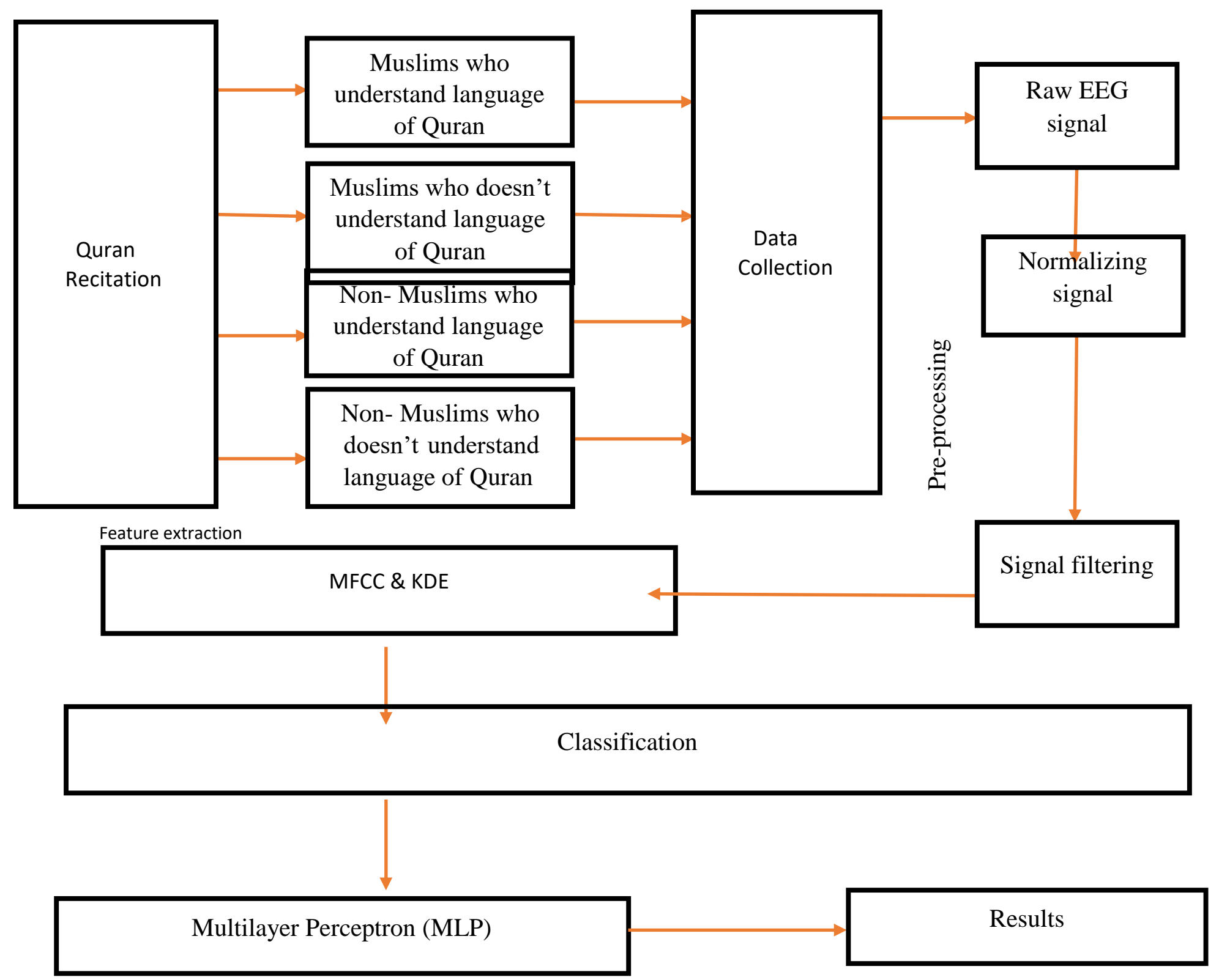

Figure 3: Proposed Methodology for Data Analysis 
Figure 3 shows the conceptual framework of the study. The participants are divided into four groups. Two groups consist of Muslims who understands and doesn't understand the language of Quran whereas the other two groups consists of non-Muslims who understands and doesn't understand the language of Quran respectively. The participants will first be exposed to Quran recitations. EEG device is used to record the brain waves while listening to Quran recitations. Algorithms are used to reduce the artifacts using filters to retrieve the filtered signals as EEG signals usually contain many artifacts due to several factors such as noise, the body movements and electrical effects in the EEG device itself. Next, feature extraction are used to extract the features from EEG signals in order to obtain only the signals that will bring benefits to the study. Classification is then done in order to classify the extracted feature. This step is done to identify the best feature to be used in the study as well as for future research.

\section{Discussion}

EEG device can be used to determine the participant's emotion while listening to Quran recitation. Based on the study by Kimiaee, Khademian, \& Farhadi, 2012, Quran has been proven to help improving one's level of stress or depression. Quran recitation has also been used in treating patients with stress or psychology problems (Mahjoob et al., 2014). Based on the study conducted by AlzeerAlhouseini, Al-Shaikhli, Abdul Rahman, \& Dzulkifli, 2016, Quran recitation has improved the emotions of the participants who were Muslims and understand and who do not understand the language of Quran. Quran recitation has also been used to treat patients for the last few years. This shows that Quran recitation will be able to improve one's emotion among non- Muslims as well. Thus, this study is conducted to determine the effect of Quran recitation on both Muslims and non-Muslims. This study is also done to compare the effect of Quran recitation among Muslims and non-Muslims who understands the language of Quran and among both Muslims and non-Muslims who doesn't understand the language of Quran using EEG device. It is hoped that through this study, all the four groups of participants; Muslims who understand and doesn't understand the language of Quran as well as non-Muslims who understand and doesn't understand the language of Quran will give positive results on the effect towards their emotion while listening to Quran recitation using EEG device.

\section{Conclusion}

The emotions determine from the participants of this study will help to provide more information to the medical field to treat stress or depressed patients. Quran recitation can then be used to treat not only Muslims but also non-Muslim patients who are suffering from stress and depressions.

\section{References}

AlzeerAlhouseini, A.M.R., Al-Shaikhli, I.F., Abdul Rahman, A.W., \& Dzulkifli, M.A. (2016). Emotion detection using physiological signals EEG \& ECG. International Journal of Advancements in Computing Technology (IJACT), 8(3), 103-112.

Atarodi, A. R., Mottaghi, M. R., \& Atarodi, F. (2012). Comparative Study on The Effect of Prayer and Praise on Peace of Mind and Physical Health from Male and Female Students' 
Points of View in Gonabad's Guidance Schools in 1390. Islamic Lifestyle Centered on Health, 1(2), 28-33.

Ebrahimi, E. (2011). Spiritual Health and psychosis in the light of Quran. Arak Medical University Journal, 13(5), 1-9.

Hamidi, F., Bagherzadeh, Z., \& Gafarzadeh, S. (2010). The Role of Islamic Education in Mental Health. Procedia - Social and Behavioral Sciences, 5, 1991-1996.

Khan, N., Ahmad, N. B., Beg, A. H., Fakheraldin, M. A. I., Alla, A. N. A., \& Nubli, M. (2010). Mental and spiritual relaxation by recitation of the holy Quran. In 2nd International Conference on Computer Research and Development, ICCRD 2010 (pp. 863-867).

Kimiaee, S. A., Khademian, H., \& Farhadi, H. (2012). Quran Memorization And Its Effect On The Elements Of Mental Health. Sociology Of Women (Journal Of Woman And Society).

Li, M., Chai, Q., Kaixiang, T., Wahab, A., \& Abut, H. (2009). EEG Emotion Recognition System. In In vehicle corpus and signal processing for driver behavior (pp. 125-135). Springer.

Mahjoob, M., Nejati, J., Hosseini, A., \& Bakhshani, N. M. (2014). The Effect of Holy Quran Voice on Mental Health. Journal of Religion and Health, 1-5.

Mottaghi, M., Esmaili, R., \& Rohani, Z. (2011). Effect of Quran recitation on the level of anxiety in athletics. Quarterly of Quran and Medicine, 1(1), 1-4.

Othman, M., Wahab, A., Karim, I., Dzulkifli, M. A., \& Alshaikli, I. F. T. (2013). EEG Emotion Recognition Based on the Dimensional Models of Emotions. Procedia - Social and Behavioral Sciences, 97, 30-37.

Siahpoosh, M. B. (2012). Six Essential Principles of Iranian Traditional Medicine for Maintaining Health from the Quran's Point Of View. Quran and Medicine, 1(4), 101107.

Wang, X.-W., Nie, D., \& Lu, B.-L. (2014). Emotional state classification from EEG data using machine learning approach. Neurocomputing, 129, 94-106.

Yordanova, J., \& Kolev, V. (2008). Event-related brain oscillations in normal. Developmental Psychophysiology: Theory, Systems and Methods, 15-68.

Zulkurnaini, N. A., Kadir, R. S. S. A., Murat, Z. H., \& Isa, R. M. (2012). The Comparison between Listening to Al-Quran and Listening to Classical Music on the Brainwave Signal for the Alpha Band. 2012 Third International Conference on Intelligent Systems Modelling and Simulation, 181-186. 